\title{
2077 Detection and differentiation of myocardial delayed contrast enhancement patterns by cardiac mri in patients with end stage renal disease

\author{
Constanze Merten*, Christoph Merbach, Vedat Schwenger, Martin Zeier, \\ Hugo A Katus, Evangelos Giannitsis and Henning Steen
}

Address: University Hospital Heidelberg, Heidelberg, Germany

* Corresponding author

from I th Annual SCMR Scientific Sessions

Los Angeles, CA, USA. I-3 February 2008

Published: 22 October 2008

Journal of Cardiovascular Magnetic Resonance 2008, IO(Suppl I):A346 doi:I0.I I86/I532-429X-I0-SI-A346

This abstract is available from: http://jcmr-online.com/content/I0/SI/A346

(c) 2008 Merten et al; licensee BioMed Central Ltd.

\section{Introduction}

Cardiovascular disease is a common complication in patients with end stage renal disease (ESRD) being the leading cause for mortality in this group of patients. From literature we know about the high prevalence of coronary artery disease among patients with ESRD with up to 50\% of patients suffering fatal myocardial infarction.

Furthermore it is known from autopsy studies that the majority of patients with ESRD develop interstitial myocardial fibrosis. Myocardial fibrosis can be accurately and non-invasively be detected by contrast-enhanced cardiac MRI.

\section{Purpose}

We sought to assess the presence of distribution patterns of delayed contrast enhancement (DCE) in patients with ESRD listed for kidney transplantation (NTX).

\section{Methods}

62 patients with ESRD listed for NTX underwent cardiac MRI using a clinical $1.5 \mathrm{~T}$ scanner. DCE (gadolinium at $0.2 \mathrm{mmol} / \mathrm{kg} \mathrm{bw}$ ) images were acquired in continuous short-axis slices covering the left ventricle (sequence). MR images were analysed by consensus-reading of two experienced observers using the 17-segment-model regarding the presence and distribution of DCE. According to its pattern DCE was classified either as ischemic-type or nonischemic-type DCE. Subendocardial and transmural DCE was classified as ischemic-type DCE. Intramural, spotted, subepicardial or diffuse DCE was classified as nonischemic-type DCE.

\section{Results}

In 4 of the 62 patients DCE image quality was insufficient, so 58 patients could be included into the final analysis. Patient characteristics are listed in table 1.

Any type of DCE of detected in a 57 of 58 patients (98\%). Differentiation of the enhancement pattern revealed evidence of prior myocardial infarction in 21 patients (36\%). Non-ischemic-type DCE was found in a total 51 of 58 patients $(88 \%)$, with most affected segments showing a spotted DCE. In 15 of the 21 patients with evidence of myocardial infarction DCE of the non-ischemic-type was seen in additional segments.

\section{Conclusion}

Myocardial infarction detected by the presence of ischemic-type DCE is a common finding among patients with ESRD listed for NTX. Additionally, our results confirm the high prevalence of interstitial myocardial fibrosis in this group of patients. As cardiovascular disease strongly influences the prognosis of patients with ESRD, the early non-invasive detection of cardiac involvement by MRI could help to guide further diagnosis and treatment. 
Table I: Patients characteristics

\begin{tabular}{ll}
\hline Age (years) & $59+/-14$ \\
\hline Male, $\mathrm{n}(\%)$ & $36(62)$ \\
Known CAD, $\mathrm{n}(\%)$ & $23(40)$ \\
Diabetes mellitu, $\mathrm{n}(\%)$ & $24(4 \mathrm{I})$ \\
ESRD due to diabetic nephropathy, $\mathrm{n}(\%)$ & $19(33)$ \\
Hypertension, $\mathrm{n}(\%)$ & $52(90)$ \\
Hyperlipidemia, $\mathrm{n}(\%)$ & $24(4 \mathrm{I})$ \\
\hline
\end{tabular}

Publish with Bio Med Central and every scientist can read your work free of charge

"BioMed Central will be the most significant development for disseminating the results of biomedical research in our lifetime. " Sir Paul Nurse, Cancer Research UK

Your research papers will be:

- available free of charge to the entire biomedical community

- peer reviewed and published immediately upon acceptance

- cited in PubMed and archived on PubMed Central

- yours - you keep the copyright 